\title{
LO INSÓLITO EN EL TEATRO LORQUIANO. LA EXTRAÑA DIMENSIÓN TEMPORAL DE ASÍ QUE PASEN CINCO AÑOS
}

\author{
ESZTER KATONA ${ }^{1}$ \\ Universidad de Szeged (Hungría)
}

\begin{abstract}
Resumen
Federico García Lorca creó la categoría dramatúrgica teatro imposible o irrepresentable para encasillar sus propias obras, sorprendentes e innovadoras, escritas en los años treinta. El presente ensayo quisiera examinar la extraña dimensión temporal de Asíque pasen cinco años, una pieza que pertenece a este teatro bajo la arena.
\end{abstract}

Palabras clave: García Lorca, Así que pasen cinco años, dimensión temporal.

\begin{abstract}
Federico García Lorca created the dramaturgical category of "impossible" or "irrepresentable theatre" in order to classify his own surprising and innovative works, written in the 1930's. In this paper I examine the strange temporal dimension of When Five Years Pass, a play that belongs to this theatre beneath the sand. Keywords: García Lorca, When Five Years Pass, temporal dimension.
\end{abstract}

\section{INTRODUCCIÓN}

Federico García Lorca, como dramaturgo, escribió unas obras teatrales inolvidables, muy conocidas por el gran público, y analizadas abundantemente por la crítica literaria, pero ya menos aplaudieron sus piezas agrupadas por el autor como teatro bajo la arena. El mismo Lorca mencionaba estas obras -El público, Así que pasen cinco años, Comedia sin título u otras piezas inacabadas- como teatro imposible o irrepresentable, aunque no está siempre claro a qué se refieren estas categorías. Ya que el género teatral en sí mismo supone un texto literario y una representación escénica, evidentemente lo irrepresentable puede aludir, por un lado, a las dificultades técnicas de la puesta en escena o, por otro lado, a una categoría mucho más estética. Realmente, la problemática de la puesta en escena de este teatro imposible está en estrecha relación, de una parte, con las cuestiones estéticas y con unas lecturas subjetivas y, de otra parte, también con el mundo más íntimo de su autor².

\footnotetext{
${ }^{1}$ Universidad de Szeged (Hungría). Correo: katonaeszter@gmail.com. Recibido: 09-02-2015. Aceptado: 09-04-2015.

${ }^{2}$ Por ejemplo, Así que pasen cinco años y El público tocan unas preocupaciones muy personales de su autor -el tema de la homosexualidad, crípticamente aún en la primera obra, abiertamente en la segunda, que
} 
La cuestión de la recepción es un punto bien complicado ya que es muy difícil formar el gusto de los espectadores educados en las "ñoñerías" del teatro español del siglo XIX. Más declaraciones de Lorca revelan que el artista granadino era muy consciente de los puntos problemáticos de sus propias obras imposibles: "no tengo la pretensión de estrenarla [...]"- dijo justamente de Así que pasen cinco años. Igualmente fue escéptico en cuanto a la posibilidad de poner en escena su otra comedia bajo la arena: "no pretendo estrenarla [...] en ninguna parte, pues creo que no hay compañía que se anime a llevarla a escena ni público que la tolere sin indignarse" - comentó su pieza, El público. ${ }^{3}$

Lo onírico, lo insólito, lo surreal, lo absurdo y lo imposible, todos entran en este cajón de sastre lorquiano, todo que con una visión peculiar quiere expresar lo inefable. Con las piezas citadas el artista granadino se adelantó al teatro de su época, imaginando lo inesperado en la escena teatral. Naturalmente, podríamos acercarnos a lo insólito de estas piezas desde diferentes puntos de vista pero, por la limitación de la extensión del presente artículo, en adelante quisiéramos concentrarnos solamente en una de las obras mencionadas, Así que pasen cinco años, y, más en concreto, nos ocuparemos del análisis del tiempo.

\section{UN RUMBO DRAMATÚRGICO NUEVO}

Durante la estancia en los Estados Unidos y Cuba, Federico García Lorca se puso a escribir un teatro completamente diferente de lo anterior. Escribió con entusiasmo a sus padres:

He empezado a escribir una cosa de teatro que puede ser interesante. Hay que pensar en el teatro del porvenir. Todo lo que existe ahora en España está muerto. O se cambia el teatro de raíz o se acaba para siempre. No hay otra solución (1997: 657).

Sin duda alguna, unas palabras muy ambiciosas y radicales, aunque no poco enigmáticas, ya que no dicen nada sobre en qué consiste esta renovación que el dramaturgo pretende realizar. Sin embargo, es descifrable su fuerte descontento con la actual situación teatral de su país natal, un disgusto que se alimentó de un teatro comercial y de calidad muy baja, imperante en aquel entonces en la vida teatral de España. El teatro auténticamente vanguardista, este teatro del porvenir, según las palabras lorquianas, lo marcarán los tres textos mencionados en la introducción.

Sin embargo, sería injusto decir que en sus piezas tempranas el dramaturgo de Fuente Vaqueros siguiera servilmente la moda teatral de los años veinte. Lo insólito y lo inusual estaban presentes ya esporádicamente en las primicias de García Lorca. En su primera obra, El maleficio de la mariposa, un rotundo fracaso en el teatro Eslava de Madrid en 1920, aparecen en la escena insectos -cucarachas y una mariposa- que hablan y se enamoran, una historia inadmisible para el público educado en el teatro burgués.

el mismo García Lorca caracterizó como un drama "de tema francamente homosexual" (García Lorca, 1997: 690)- así, con su puesta en escena Lorca habría abierto su intimidad ante el público, se habría quedado desnudo ante todo el mundo.

${ }^{3}$ De una entrevista dada por García Lorca en Buenos Aires. Lo cita José Monleón (1977: 51). 
El mismo tema, con un tratamiento melodramático y almibarado, seguramente habría cosechado un éxito clamoroso. O, en otra pieza, La tragicomedia de Don Cristóbal y la señá Rosita, aparece una Hora que habla. Además, basta pensar en la figura de la loca abuela, María Josefa de La casa de Bernarda Alba, para entender hasta qué punto cruza la obra lorquiana la "resistencia a aceptar la vida como algo escolásticamente explicable" (Monleón, 1977: 51), aunque claro está, que la locura de la abuela pertenece a otra categoría teatral y tiene función bien distinta.

Aunque en el género guiñolesco -al que pertenece la citada Tragicomedia- los objetos hablantes no son tan raros, sin embargo, ya estos ejemplos pueden apoyar la idea de Lorca sobre el teatro, resumido así en una entrevista de 1931: “ [...] haré el teatro [...] como me dé la gana." ${ }^{4}$ El público, Así que pasen cinco años y Comedia sin título constituirán, sin duda alguna, la cumbre de esta arbitrariedad teatral, una revolución desgraciadamente inacabada por la temprana muerte de Federico García Lorca.

La posterioridad suele justificar la tardía difusión de estas obras con su difícil entendimiento y accesibilidad por parte del público. Eso es verdad solamente en parte, ya que la demora de estas obras en llegar a los lectores (y a las tablas) se debe obviamente a motivos editoriales estrechamente unidos a las circunstancias políticas de la España franquista. Aunque Lorca escribió El público en 1930, la primera edición completa no vio la luz hasta 1976, con el prólogo y la transcripción de Martínez Nadal (García Lorca: 1976). El manuscrito de Así que pasen cinco años lleva la fecha 19 de agosto de 1931 -una coincidencia escalofriante, exactamente cinco años más tarde será fusilado su autor- y fue editado por primera vez en Argentina (García Lorca: 1938), y en España, con el estudio y las notas de Martínez Nadal, solo cuatro décadas más tarde (García Lorca: 1979). La Comedia sin título fue la más tardía en su edición española: apareció solamente en los años ochenta, dentro del tomo Teatro inconcluso (García Lorca: 1987).

En ocasión del estreno de La zapatera prodigiosa el mismo Lorca dijo a un periodista que todo el teatro anterior "No, no es mi obra. Mi obra vendrá... ¿Sabes cómo titulo mi obra? El Público. Esa sí..., ésa... Dramatismo profundo, profundo" (citado por Gibson, 2009: 270). Desgraciadamente este entusiasmo no encontró a su público en la vida de Lorca, sin embargo, las palabras evocadas expresan bien la importancia de estas piezas -injustamente consideradas como menores durante muchas décadas- dentro de la obra artística del granadino.

\section{LA POSIBLE INFLUENCIA DE LA TEORÍA EINSTEINIANA}

Ian Gibson opina con razón que Así que pasen cinco años es la obra donde Lorca logra fundir con una admirable armonía lo tradicional con lo contemporáneo (2010: 470). Por consecuencia, no podemos pasar por alto que este teatro, incluso en su innovación, está arraigado en unas innegables tradiciones teatrales, aunque

${ }^{4}$ Palabras de García Lorca en la revista Miradero, recuperada por el Centro de Documentación Teatral (Sigüenza, 2012). 
dificulta mucho el mapeo de las influencias sobre García Lorca que el poeta utilizó "por intuición" y "por contaminación" (Francisco García Lorca 188) las vanguardias de su tiempo. Por su "facilidad extraordinaria para asimilar y aprovechar cualquiera corriente literaria o artística" (palabras de Ángel del Río en García Lorca, 1958: 37), es casi imposible dar un cuadro completo sobre estas "contaminaciones", en cuanto a la obra aquí analizada, aunque el excelente análisis de Margarita Ucelay (García Lorca, 2010: 36-64) intentó con éxito dibujar un cuadro exhaustivo. Entre las influencias cronológicamente más cercanas, es decir de las tendencias del siglo $\mathrm{XX}$, tenemos que destacar la del surrealismo -aunque García Lorca nunca aceptó la escritura automática de la escuela de André Breton-, la de la interpretación de los sueños de Sigmund Freud, el influjo del cine mudo ${ }^{5}$ y el teatro vanguardista de Nueva York, conocido por García Lorca durante su estancia americana. De "las contaminaciones" del siglo XIX sobresale el entusiasmo del dramaturgo de Fuente Vaqueros por Víctor Hugo -es perceptible la influencia de la Leyenda del apuesto Pécopin y de la bella Bauldour ${ }^{6}$-, y por el teatro romántico español, donde aparece recurrentemente el motivo de la espera (Los amantes de Teruel de Hartzenbusch, Macías de Mariano José de Larra) o el desdoblamiento del protagonista (El Estudiante de Salamanca de Espronceda). Además, la obra de García Lorca muestra reminiscencias del drama El sueño de Agust Strindberg, publicado en 1902, una obra que sigue la lógica del estado de ensoñación, igual a la perspectiva del Joven del drama lorquiano.

En el bagajeliterario de García Lorca se figuraban también los autos sacramentales y los misterios medievales (basta pensar en el alegorismo del Presente, el Pasado y el Futuro, personificados en Así que pasen cinco años por los dos Amigos y el Viejo), como tampoco podemos negar el interés del autor por la commedia dell'arte. Este último aparece tanto en el uso de algunos personajes característicos del género (el Arlequín y el Payaso en el tercer acto), pero Lorca los aprovecha también en su función de metateatro.

Repasando los ejemplos mencionados, podemos observar que en más de estos es muy importante la visión particular de los autores sobre el tiempo. Entre las influencias aún no hemos mencionado una fuente inspiradora importante, la propia poesía juvenil de Lorca. El poema Aire nocturno (1919) o las piezas de las Suites dejaron evidentemente sus huellas en la obra onírica de 1931, y en estos casos otra vez nos chocamos con la problemática del tiempo. El tema es un motivo literario y filosófico de muchos siglos $\mathrm{y}$, por supuesto, podríamos citar numerosos ejemplos más también

\footnotetext{
${ }^{5}$ Es indudable la huella de Un perro andaluz de Buñuel y Dalí, por ejemplo, en las frases de la Mecanógrafa: “No me asomaba. Pero... lo veía por las rendijas... quieto (Saca un pañuelo.), jcon unos ojos! Entraba el aire como un cuchillo, pero yo no le podía hablar." (García Lorca, 2010: 305) - donde la alusión a la emblemática secuencia del filme con el ojo y el cuchillo es evidente. Un análisis comparativo véase en el artículo de Higginbotham.

${ }^{6}$ Para destacar algunos paralelismos entre las dos obras: Pécopin permanece lejos de su amada cinco años; Bauldour tiene quince años como la Novia de la obra lorquiana; Pécopin, a su regreso a casa, se encuentra con Bauldour que está hilando, convertida en una Parca mitológica, al igual que los tres Jugadores de Lorca son la personificación disfrazada del Fatum. Véase más detalladamente en Eutimio Martín (1986: 123-130).
} 
del siglo XX, sin embargo, aquí solamente destacaríamos una de éstas, justamente una no estrictamente artística y que los escritos analíticos sobre Así que pasen ... aún no han detallado mucho: la famosa teoría de la relatividad de Einstein que cambió nuestras nociones sobre el espacio y el tiempo.

El gran físico alemán visitó España en marzo de 1923 y durante su estancia7 en la capital tuvo una conferencia incluso en la Residencia de Estudiantes, el famoso Oxford madrileño. Es bien sabido que entre las paredes de la célebre institución se desarrolló una animada vida científica. Allí vivieron unos miembros destacados del Instituto Nacional de Física y Química, dirigido por el físico Blas Cabrera, y también fue estrecha la relación de los residentes con el Museo Nacional de Ciencias Naturales, bajo la dirección de Ignacio Bolívar. Rasgo específico de la enseñanza de las ciencias naturales en la Residencia fue que los científicos no formaban una "casta" severamente separada de mentes excelentes sino que los laboratorios modernos estaban abiertos a los alumnos de otras facultades. Estudiantes de artes, de filología o de filosofía pudieron así visitar estos establecimientos para conocer desde cerca las investigaciones de sus compañeros y de los científicos más importantes del primer tercio del siglo. ${ }^{8}$ Existía, por tanto, una convivencia entre el pensamiento científico y el resto de la cultura, como constata Ángel Vivas: "en la Colina de los Chopos, no solo se dibujaron putrefactos, se leyó con pasión a Freud y se incubaron proyectos surrealistas" sino que la física -la ciencia por excelencia para muchos- ocupó un lugar destacado. Así, a pesar de que la mayoría del alumnado no tuvo la necesaria formación matemática y física para entender el razonamiento del huésped alemán, el entusiasmo de los residentes fue enorme. Además, hay que añadir que Einstein mismo ayudó la difusión de su teoría con unos simples aforismos como, por ejemplo, el siguiente: “Cuando cortejas a una bella muchacha, una hora parece un segundo. Pero te sientas sobre carbón al rojo vivo, un segundo parecerá una hora. Eso es relatividad" (Einstein, genio y filósofo). Sin duda alguna, con la sencillez de la frase arriba citada, el creador de la Relatividad hizo ya mucho más entendible su concepto e intentó introducir al público sin conocimientos previos a la tierra incógnita de la física.

En las biografías consultadas sobre García Lorca no hemos encontrado ninguna referencia concreta a que el joven poeta estuviera presente en persona en el público de la conferencia de Einstein, pero es seguro que por esas fechas Federico vivía en la Resi ${ }^{9}$ $\mathrm{y}$, por la envergadura del acto, podemos suponer que participó personalmente en el

${ }^{7}$ El Premio Nobel de Física pasó unos días en Barcelona (23-28 de marzo), en Madrid (1-11 de marzo) y en Zaragoza (12-14 de marzo) (Cronología del viaje de Einstein).

${ }^{8}$ Por ejemplo, es conocida la foto de García Lorca (1922) donde el poeta aparece sentado delante de un microscopio. Asequible en la galería de imágenes ( $10^{\mathrm{a}}$ foto) de elcultural.es (Centenario). Otra imagen apoya la afición de Salvador Dalí por las ciencias: el pintor catalán en 1927 se posa con sus amigos -entre ellos García Lorca también- sosteniendo bajo su brazo un número de la revista Science and Invention (Exposición Gallo).

${ }^{9}$ García Lorca llegó a la Residencia de Estudiantes en 1919. Después de una ausencia de año y medio (motivada por la organización -en colaboración con Manuel de Falla- del Concurso de Cante Jondo en Granada y por las obligaciones universitarias, tuvo que terminar su carrera de derecho) volvió a la capital en febrero de 1923. 
acontecimiento irrepetible. Además, por la difusión de la prensa madrileña llena de las crónicas sobre Einstein durante las primeras dos semanas de marzo, García Lorca estaba seguramente al corriente de las noticias.

Es verdad que Lorca en su niñez y adolescencia no fue un buen alumno -según sus propias confesiones recibió unos "cates colosales" (Gibson, 2010: 69, Magariño 36)-, tuvo grandes dificultades en el estudio de las asignaturas de ciencias naturales, entre ellas la física y las matemáticas. Así, es evidente que Lorca, sin conocimientos profundos sobre el cálculo diferencial, no pudo captar la esencia científica de la teoría einsteiniana, pero la relatividad le interesaba mucho más desde una posible interpretación artística. Los extraños planos temporales de Así que pasen cinco años logran perfectamente expresar la cuarta dimensión, a la manera de unos "relojes blandos" dalinianos.

\section{LA DIMENSIÓN TEMPORAL DE ASÍ QUE PASEN CINCO AÑOS}

Así que pasen cinco años es un texto denso en el que podemos encontrar todos los grandes motivos del mundo de García Lorca: la frustración amorosa, la angustia ante el paso del tiempo, el horror a la vejez por el extremo temor lorquiano a la muerte, el ansia de paternidad/maternidad, la imagen de la mujer como un ser hecho de ilusión engañosa y destructora y, por fin, la problemática más lorquiana, la necesidad de la expresión más íntima y sincera, acompañada siempre por un temor ante la reprobación y el rechazo de la sociedad. De esta gran complejidad de motivos quisiéramos detallar ahora solo la cuestión del tiempo como problemática central de este mundo onírico.

El tiempo como tema aparece desde temprano en la obra poética de Federico García Lorca, muy marcadamente en los poemas del ciclo Suites cuya composición se fija entre finales de 1920 y agosto de $1923 .{ }^{10}$ Dentro de este período no conocemos con exactitud las fechas de los manuscritos de cada una de las piezas, sin embargo, es de suponer que algunos de los poemas nacieron después de que Lorca había conocido la teoría de Albert Einstein sobre la Relatividad. ${ }^{11}$ Por ejemplo, en Meditación primera y última García Lorca escribe unas frases que no necesitan explicación alguna: “Y el Tiempo se ha dormido / para siempre en su torre. / Nos engañan / todos los relojes. / El Tiempo tiene ya / horizontes" (2014: 31). Visión semejante recibimos sobre el tiempo dormido en la imagen de "la torre sin campanas" (en el poema Pueblo, 2014:22) y en la de los "relojes de cuco, / sin cuco" (en el poema Maleza, 2014: 29).

El tiempo parado aparece también en La selva de los relojes donde el poeta se pierde entre las frondas del tic-tac, racimos de campanas y constelaciones de péndulos.

\footnotetext{
${ }^{10}$ El tomo no se publicó en la vida de García Lorca y los poemas que más tarde formarían el libro de la edición de Belamich (García Lorca 1983) estaban dispersos, algunos publicados en revistas, otros en unas cartas escritas por Lorca a sus amigos, o conservados entre los papeles privados del poeta, sin ordenación y derecho de publicación durante más décadas (García Lorca, 2010: 59).

${ }^{11}$ El gran físico alemán dio su famosa conferencia en la Residencia de Estudiantes de Madrid el 9 de marzo de 1923.
} 
El poema concluye así: “Hay una hora tan sólo. / ¡Una hora tan sólo! / ¡La hora fría!” (2014: 29).

El carácter misterioso y la entidad inexplicable del tiempo se manifiestan tanto en el título La hora esfinge (2014: 31) como en los versos "La verdadera esfinge / es el reloj." (2014: 30) también del tomo de las Suites.

Pensamos que los versos citados demuestran suficientemente que el reloj, el tiempo y la hora son motivos reiterantes de este ciclo del joven poeta. Su influencia no se la olvidará García Lorca tampoco unos años más tarde, cuando en su obra dramática aparecerá otra vez la cuestión del tiempo.

Quizás, la evocación de la mencionada hora fría puede ser el punto de partida de la visión onírica de Así que pasen cinco años. Leyenda del tiempo $(1931)^{12}$, una pieza irrepresentable de Lorca que, sin duda alguna, desarrolla más complejamente la relación muy particular del dramaturgo con el tiempo.

El argumento de Así que pasen cinco años es muy simple y resumible en algunas frases. Un joven espera casarse con su novia "así que pasen cinco años". Terminada la espera, el joven busca a la mujer, pero ella no le ama ya, y se va con otro hombre. El joven recuerda a la Mecanógrafa que hace cinco años le amaba y decide buscarla para no perder la posibilidad de amar y ser amado. Esta vez es la mujer, la Mecanógrafa, que quiere esperar y, por eso, le propone al joven otra espera de cinco años. El joven se queda solo y muere. Esta aparente sencillez argumental oculta unos significados muy profundos con una dimensión temporal rara, pues todo eso exige una atención aguda para entender realmente la obra.

Al parecer, el mismo título de la pieza nos insinúa ya la importancia del tiempo. Lorca utiliza una frase cortada que sugiere inseguridad (¿qué sucederá cuando pasen cinco años?) y un subtítulo que hace referencia al subgénero (leyenda ${ }^{13}$ ) de la obra. No solamente el título, sino también el mismo dramaturgo especificó como tema de su obra "el tiempo que pasa" (García Lorca, 1974: 914). Así no hay motivo por qué dudar en eso, es decir el tema principal, incluso el verdadero protagonista de la obra es el

\footnotetext{
${ }^{12}$ A pesar del inicial pesimismo sobre la representabilidad de la pieza, el primer intento de una puesta en escena de Así que pasen cinco años fue en mayo de 1936, bajo la dirección de Pura Ucelay, con la colaboración del mismo Lorca, sin embargo, el rumbo de los acontecimientos políticos de España obligaron al Club Teatral Anfistora a posponer el estreno que, por la muerte del autor en agosto, al final no se realizó nunca. La obra quedó bajo la arena en la España franquista durante cuarenta años, hasta 1975, cuando un grupo de jóvenes estudiantes aficionados del Liceo Francés de Madrid la puso en escena (García Pavón 62). Luego, la primera puesta en escena de una compañía profesional española fue en 1978, bajo la dirección de Miguel Narros (López Sancho 47-48). El primer estreno fuera de España de Así que pasen cinco años fue en 1958 en Puerto Rico, bajo la dirección de Victoria Espinosa. El debut en Europa fue en París (1959), en el Teatro Recamier, bajo la dirección y traducción de Marcelle Auclair (García Requena 88-89).

${ }^{13}$ Lorca antes usaba también el misterio para hacer referencia al género de su drama, aludiendo a los misterios y autos sacramentales de la Edad Media. Sin embargo, opina Ucelay, la elección final del subtítulo, como leyenda, muestra evidentemente la influencia de Víctor Hugo y de su mencionada Leyenda del apuesto Pécopin y de la bella Bauldour (García Lorca, 2010: 50). Apoyan esta idea más poemas de la juventud de Lorca y las memorias de su hermano, Francisco que dan testimonio sobre la influencia del gran novelista francés sobre Federico (Francisco García Lorca 50; Gibson, 2010: 31-32).
} 
tiempo. En cuanto a la dimensión temporal de la obra José Monleón opina con razón que Así que pasen cinco años es un verdadero y "delicadísimo rompecabezas" (1978: 51). El dramaturgo, aunque respeta la estructura de los tres actos, rompe el tradicional teatro gobernado por las tres unidades de tiempo, acción y espacio. La construcción aparentemente desordenada del tiempo hace difícil la interpretación y Fernández Cifuentes opina con razón que:

[...] es una obra de teatro sobre el tiempo empeñada en perturbar las firmes convicciones de tiempo en el teatro. La alteración o el desorden de ese curso convencional es a la vez el objeto y el procedimiento de la obra (264).

Al comienzo de Así que pasen cinco años aparece un reloj ${ }^{14}$, pero que no sirve para medir el tiempo real sino que justamente marca la inmovilidad del tiempo, de modo semejante al tiempo dormido en su torre de la suite Meditación primera y última. En el drama el reloj toca las seis horas al inicio de la obra ${ }^{15}$. En el segundo acto, al parecer, hay un salto de cinco años en la cronología (la Novia regresa de su viaje de cinco años) $\mathrm{y}$, al final de la obra, vuelve el reloj del primer acto dando las doce que, en realidad, podemos interpretarlas como las seis horas duplicadas solamente por el eco. ${ }^{16}$ García Lorca omite del paso del tiempo y lo trata arbitrariamente. Eso también explica el mismo rasgo onírico de toda la obra, ya que solamente el sueño puede prescindir de la regla del flujo tradicional del tiempo. Es decir, estamos ante una historia atemporal, que se desarrolla solamente en la mente del protagonista, fuera de la realidad y la lógica racional.

También dificulta la interpretación de la obra que es muy engañoso cómo utiliza Lorca las diferentes partes del día. El primer acto comienza con una tarde (el reloj da las seis), en el segundo acto es de noche (alusión a la luna y la eclipse), en la misma noche se desarrolla la escena del bosque, y el último cuadro, que tiene lugar en la biblioteca del primer acto, también repite la misma hora del comienzo del drama. Es decir, junto a la verdadera inmovilidad temporal, podemos notar una aparente construcción circular también.

La repetida alusión al Niño y el Gato muertos sirve igualmente para confundir la dimensión cronológica de la obra. En el primer acto en las acotaciones podemos leer que "aparece el Niño muerto con el Gato" (García Lorca, 2010: 217) y del diálogo de las dos figuras entendemos que el Gato y el Niño acaban de morir. En el segundo

\footnotetext{
${ }^{14}$ Es interesante notar aquí que el dramaturgo utilizó el reloj (o, mejor dicho, la Hora) como personaje en su obra Los títeres de Cachiporra (1923), donde el objeto animado tampoco sirve para medir el tiempo real sino que aconseja a Rosita que espere: " [...] ten paciencia [...] Deja que el agua corra y la estrella salga. ¡Rosita, ten paciencia!" La alusión al agua que corre nos hace pensar en la famosa idea de Heráclito evocada más tarde, como vamos a citar, también en las palabras del Viejo de Así que pasen cinco años.

${ }^{15}$ ¿Por qué elige Lorca justamente las seis horas? En una pieza que pertenece al teatro breve de Lorca, con el título Quimera, también un reloj da las seis. Pensamos que su preferencia por el número seis no puede ser una pura casualidad ya que la doble de las seis horas -duplicada por el eco- las doce simbolizan la eternidad, equivalente a la hora fría y última del reloj, es decir, la de la muerte (García Lorca, 2010: 87).

${ }^{16}$ Es interesante que Lorca utiliza el eco para doblar la voz de las horas también en uno de sus poemas dentro del ciclo Suites: "Eco del reloj / los doce flotantes números negros" (2014: 31). En el tomo hay, además, una poesía que tiene el título Eco del reloj (2014: 30).
} 
acto -aunque aparentemente han pasado ya cinco años- el gato está muriendo ("en la calle he golpeado a unos niños que estaban matando un gato a pedradas" - dice el Joven (García Lorca, 2010: 265)). En el último acto, el Niño muerto cruza la escena y la Máscara amarilla, madre supuesta del Niño, también mueve en esta confusión de los planos temporales, no sabiendo en cuál de los dos (pasado, presente) está viviendo. En la última escena, de las palabras del Criado llegamos a saber que acaban de enterrar al Niño muerto. Estas situaciones paralelas sugieren la simultaneidad temporal de la obra y el tiempo da vueltas en su aparente inmovilidad.

Es constante la alusión al tiempo también en los diálogos de la obra que tienen un matiz irracional y surrealista justamente por el tratamiento especial de la cuarta dimensión. El primer diálogo de la obra entre el Viejo y el Joven se ocupa del tiempo y aborda la cuestión del recuerdo: "hay que recordar, pero recordar antes [...] hay que recordar hacia mañana" (García Lorca, 2010: 194) - dice el Viejo. El acto de recordar, que normalmente se refiere al pasado, en esta situación onírica recibe un tono ilógico y una perspectiva hacia el futuro.

Es interesante la respuesta de Lorca -dada en palabras de uno de sus personajesa la cuestión ¿cómo medir el tiempo? Según el Viejo, el paso del tiempo hay que medirlo no con años, sino con otras formas menos usuales: "Pero, ¿por qué no decir tiene quince nieves, quince aires, quince crepúsculos?", o con lunas, rocas o nortes de nieve (García Lorca, 2010: 198, 324), una cronología rara, subjetiva y relativa.

Dos personajes -el Amigo $1^{\circ}$ y el Amigo $2^{\circ}$ - tienen mucho que ver también con el tiempo y subrayan la existencia del tiempo psicológico. El primer Amigo es el presente, representante del Carpe diem, es el gran "consumidor del tiempo" que repite más veces que "no tengo tiempo" (García Lorca, 2010: 211-212). El otro amigo simboliza el pasado, el recuerdo, se expresa muy poéticamente: “Quiero morirme siendo amanecer, / quiero morirme siendo/ ayer" (García Lorca, 2010: 237). Estos versos aparecieron ya años antes, entre los poemas tempranos del poeta, con el título Suite del Regreso y citados, probablemente por primera vez, en una carta escrita el 13 de octubre de 1923 a Melchor Fernández Almagro (García Lorca, 1997: 212). El personaje del drama no solamente quiere vivir en el recuerdo "sino que aspira a una vida regresiva, a un retorno hacia la fuente originaria" (Francisco García Lorca 328). En el diálogo entre el Joven y la Mecanógrafa vuelve la reminiscencia de Aire de nocturno, otro poema juvenil de Lorca: “Mecanógrafa. ¿Qué es eso que suena muy lejos? Joven. Amor, / el día que vuelve. / ¡Amor mío!” (García Lorca, 2010: 316).

El personaje del Viejo ya mencionado simboliza el futuro; es un tipo de guardián que proyecta lo que va a suceder con el protagonista y por eso -para no gastarse y para que no llegue la muerte- quiere hacer durar el tiempo y es partidario de la espera como algo hermoso y útil.

La meditación sobre el tiempo está presente también en la frase del Viejo, una frase de clara inspiración heraclítica sobre el perpetuo devenir y del fluir: "El agua que viene por el río es completamente distinta de la que se va" (García Lorca, 2010: 202). Algunos diálogos rozan ya lo absurdo justamente por el tratamiento temporal: "Se me 
olvidará el sombrero... [...] es decir, se me ha olvidado el sombrero" (García Lorca, 2010: 214-215) - juega el Viejo con los tiempos. Semejante impresión nos da la discusión entre el Viejo y los amigos (“Viejo. Sí, sí pero lo pasado, pasado. Amigo 1. Pero si está pasando." (García Lorca, 2010: 231-232) y “Amigo 2. (Sereno.) ¡Claro! ¡Todo eso pasa más adelante! Viejo. Al contrario. Eso ha pasado ya" (García Lorca, 2010: 240)).

Como hemos visto, inmovilidad, circularidad y simultaneidad todas caben en la dimensión cronológica de esta obra-sueño. Unas dimensiones subjetivas y arbitrarias o, podríamos decir, refiriéndonos a Einstein, muy relativas. Los planos del tiempo se intercambian y dan origen a la completa deconstrucción de la sintaxis temporal de la pieza analizada que pertenece -según la definición lorquiana- a su teatro bajo la arena.

\section{A MODO DE CONCLUSIÓN}

Hemos mencionado que la meditación sobre el tiempo de la poesía juvenil de García Lorca vuelve en la obra analizada y, como hemos visto, incluso aparecen en ésta citas de algunos versos tempranos. Por último, es importante también aludir a la relación entre Así que pasen... y el Romance del emplazado, perteneciente al tomo Romancero gitano (1928), aunque esta vez no se trata de una analogía textual. En el poema citado se le predice a el Amargo su muerte inminente contra la que nada puede hacer. Al hombre, señalado funestamente por la muerte, sólo le queda resignarse y esperar estoicamente el cumplimiento del destino. De modo semejante al Amargo del romance, tampoco el Joven de Así que pasen... puede cambiar el rumbo de su vida. Pero no solamente en la evocación de este sentimiento, sino también en la estructura cronológica podríamos comparar el poema y la pieza teatral, visto que ambos mezclan magistralmente los planos temporales, y el desorden lógico refuerza aún más el aspecto onírico de las dos obras. La mención de los naipes helados (naipes como objeto que predice el futuro, pero helados porque anuncian la muerte) puede evocarnos el juego mortal al final de la Leyenda del tiempo donde el Joven, al recibir los naipes, observa: “iQué cartas más frías!" (García Lorca, 2010: 345). Además, ambos hombres aparecen como sonámbulos: el Amargo espera la muerte con ojos que no pueden cerrarse por la noche, mientras que el Joven aparece vestido de pijama azul al comienzo del drama. Tal vez, podemos notar un paralelismo también entre la cruz pintada en la puerta del Amargo y el as de coeur del Joven, ya que ambos simbolizan un blanco inconfundible para la muerte. ${ }^{17}$

De la obra lorquiana podríamos elegir un sinfín de ejemplos que atestiguan la fuerte relación entre poesía y teatro, pero pensamos que el ejemplo citado apoya perfectamente la opinión del granadino: "El teatro es la poesía que se levanta del libro y se hace humana. [...] El teatro necesita que los personajes que aparezcan en la escena lleven un traje de poesía y al mismo tiempo que se les vean los huesos, la sangre" (García Lorca, 2008: 730).

\footnotetext{
${ }^{17}$ Es, tal vez, una observación interesante que García Lorca dedicó el poema del Emplazado a su íntimo amigo, el escultor Emilio Aladrén cuyo rechazo provocó en el poeta fuerte sentimiento de depresión. Conociendo este detalle, aludiríamos a nuestra nota $1^{\text {a }}$ donde hemos referido al tema de la homosexualidad en Así que pasen cinco años.
} 
La problemática del tiempo -el paso del tiempo, el tiempo vivido $\mathrm{y}$ experimentado y el del estado de ensoñación- es un tema recurrente de los escritores del siglo XX. Aquí no hay suficiente espacio para profundizarnos en cómo aparece la misma cuestión desde Proust hasta autores españoles tanto de la generación de 98 como del grupo poético de 27, al que perteneció García Lorca también, o las vanguardias de los años 20 y 30. Visto que la crítica literaria analizó abundantemente este tema en la obra de más autores -Unamuno, Azorín, Cernuda, Gómez de la Serna, para citar algunos ejemplos españoles-, aquí solamente añadiríamos un ejemplo más, un cuento interesante y menos conocido de Luis Buñuel, con el título Por qué no uso reloj ${ }^{18}$, escrito justamente en 1923, solamente dos meses después de la visita de Einstein en la Residencia, y que igualmente atestigua -con humor e ironía- la huella de la teoría sobre la Relatividad. Junto a este ejemplo literario podríamos enumerar más pinturas de Dalí, donde aparecen unos relojes, a veces muy extraños, como en el caso del cuadro La persistencia de la memoria. Los famosos relojes blandos del pintor catalán nacieron en 1931, el mismo año en que Lorca redactó Así que pasen cinco años. Aunque, por supuesto, no podemos eliminar tampoco las otras influencias tanto estéticas como ideológicas de la época en la obra de los artistas mencionados, pensamos que "los tres mosqueteros" de la Resi podían aprovechar también las ideas del ilustre físico alemán ${ }^{19}$, mezclándolas con otros influjos y transformándolas en literatura o en pintura.

Si repasamos la obra teatral de García Lorca posterior a Así que pasen cinco años, podemos constatar que el tema del tiempo (y de la espera) es objeto de desarrollo dramático también en el drama Doña Rosita o el lenguaje de las flores (1935) aunque en éste la misma problemática está tratada de muy diferente manera. En "el poema granadino" -como afirma Francisco García Lorca- "la acción es, esencialmente, el paso del tiempo; del tiempo cronológico. Doña Rosita [es] el tiempo en acción." Mientras que en la Leyenda del tiempo "se dramatiza la emoción del tiempo, y es el sentimiento del tiempo como dilación, como inminencia" (322).

Muchos escritos nacieron sobre la cuestión de la imposibilidad de las obras lorquianas categorizadas por el inmortal granadino bajo el ya citado lema teatro bajo la arena. En el presente ensayo no hemos detallado las diferentes teorías sobre este concepto, sin embargo, pensamos que justamente la dimensión cronológica y la enigmática sintaxis temporal -que realmente implican dificultades para una representación escénica- pueden constituir uno de los motivos de la irrepresentabilidad lorquiana.

\footnotetext{
${ }^{18}$ La narración breve fue publicada por primera vez en la revista cultural Alfar (número 29, 1923) y más tarde en el tomo de Obra literaria de Luis Buñuel.

${ }^{19}$ Luis Buñuel llegó a la Residencia en 1917, Salvador Dalí en 1922. El pintor de Cadaqués interrumpió su estancia en Madrid cuando fue expulsado de la Academia de Bellas Artes en noviembre de 1923. Por consecuencia, en marzo de 1923, ambos estaban entre los residentes.
} 


\section{BIBLIOGRAFÍA}

Buñuel, Luis (1982): Obra literaria. Introducción y notas de Agustín Sánchez Vidal, Zaragoza, Heraldo de Aragón.

"Centenario de la Residencia de Estudiantes. Galería de Imágenes", sin autor. http:/ / www. elcultural.es/galerias/galeria_de_imagenes/224/ARTE/Centenario_de_la_ Residencia_de_Estudiantes_de_Madrid. (Consultado el 11 de octubre de 2014). Véase la foto 10: Lorca sentado delante del microscopio.

“Cronología del viaje de Einstein a España, 1923”, sin autor. (2005): Quark, 36 (mayoagosto), 54-56. http://quark.prbb.org/36/036054.pdf. (Consultado el 29 de septiembre de 2014).

"Einstein, genio y filósofo", sin autor. (2005): ABC, 11 de mayo. http://www.abc.es/ sociedad/20130511/rc-einstein-genio-filosofo-201305110816.html. (Consultado el 21 de febrero de 2015).

"Exposición Gallo. Interior de una revista. 1928", sin autor. La foto sobre Dalí: http:// www.residencia.csic.es/gallo/exposicion/gallo_2.htm (Consultado el 30 de septiembre de 2014).

Fernández Cifuentes, Luis (1986): García Lorca en el teatro: la norma y la diferencia, Zaragoza, Prensas Universitarias.

García Lorca, Federico (1923): Los títeres de cachiporra, Disponible en: http:// federicogarcialorca.net/obras_lorca/los_titeres_de_cachiporra.htm (Consultado el 11 de octubre de 2014).

García Lorca, Federico (1938): Obras completas, Buenos Aires, Losada.

García Lorca, Federico (1958): Poeta en Nueva York, Introducción de Ángel del Río, Madrid, Taurus.

García Lorca, Federico (1974): Obras completas, Tomo II, Madrid, Aguilar.

García Lorca, Federico (1976): El público. Autógrafos II. Prólogo, versión depurada y transcripción de Martínez Nadal, Oxford, The Dolphin Book.

García Lorca, Federico (1979): Así que pasen cinco años. Autógrafos III. Estudio, transcripción y notas de Martínez Nadal, Oxford, The Dolphin Book.

García Lorca, Federico (1983): Suites, Edición crítica de André Belamich, Barcelona, Ariel.

García Lorca, Federico (1987): Teatro inconcluso: fragmentos y proyectos inacabados, Granada, Fundación Federico García Lorca.

García Lorca, Federico (1997): Epistolario completo, Madrid, Cátedra.

García Lorca, Federico (2008): Obra completa VI. Prosa 1. Edición de Miguel García Posada, Madrid, Akal.

García Lorca, Federico (2010): Así que pasen cinco años. Edición e introducción de Margarita Ucelay, Madrid, Cátedra. 
García Lorca, Federico (2014): Suites. Digitalizado por librodot.com. Disponible en: http:/ / severitorres.org/ampa/joomla/images/Biblioteca/G/garcialorca/ suites.pdf (Consultado el 4 de octubre de 2014).

García Lorca, Francisco (1980): Federico y su mundo, Madrid, Alianza.

García Pavón, Francisco (1975): “Así que pasen cinco años: emoción y poesía de Lorca”, Blanco y Negro, (29 de marzo), 62.

García Requena, Federico (1959): “A los veintisiete años de haber sido escrita se estrena en París la obra de Federico García Lorca Así que pasen cinco años", Blanco y Negro, (17 de enero), 88-90.

Gibson, Ian (2009): Lorca y el mundo gay, Barcelona, Planeta.

Gibson, Ian (2010): Vida, pasión y muerte de Federico García Lorca, Barcelona, De Bolsillo. Higginbotham, Virginia (1986): “Así que pasen cinco años: Una versión literaria de Un Chien andalou", Cuadernos hispanoamericanos, números 433-434 (julio-agosto), 343-350.

López Sancho, Lorenzo (1978): “Así que pasen cinco años, una profunda dimensión teatral de García Lorca", $A B C$, (22 de septiembre), 47-48.

Magariño, Arturo (1983): García Lorca. Biblioteca histórica. Grandes personajes, Madrid, Ediciones Urbión.

Martín, Eutimio (1986): Federico García Lorca, heterodoxo y mártir. Análisis y proyección de la obra juvenil inédita, Madrid: Siglo XXI.

Monleón, José (1977): “El público de García Lorca”, Triunfo, 729, (15 de enero), 51.

Monleón, José (1978): “Así que pasen cinco años y el público español”, Triunfo, (21 de octubre), 50-51.

Sigüenza, Carmen (2012): “García Lorca: Haré el teatro como me dé la gana”, Diario de Sevilla (24 de febrero),

http://www.diariodesevilla.es/article/ocio/1192477/garcia/lorca/hare/ teatro/como/me/la/gana.html (Consultado el 10 de octubre de 2014).

Vivas, Ángel (2013): “La vanguardia científica en la Residencia de Estudiantes”, El Mundo (11 de octubre), http:/ / www.elmundo.es/elmundo/2013/10/11/ ciencia/1381488851.html (Consultado el 29 de enero de 2014). 